\title{
Antitumorigenic action of nelfinavir: Effects on multiple myeloma and hematologic malignancies (Review)
}

\author{
A. ALlEGRA, V. INNAO, A.G. ALLEGRA, N. PULVIRENTI, M. PUGLIESE and C. MUSOLINO \\ Division of Hematology, Department of Human Pathology in Adulthood and Childhood 'Gaetano Barresi', \\ University of Messina, I-98125 Messina, Italy
}

Received November 6, 2019; Accepted February 17, 2020

DOI: $10.3892 /$ or.2020.7562

\begin{abstract}
Protease inhibitors (PIs) inhibit HIV-1 and HIV-2 proteases, impeding virus replication and liberation of viral elements from infected cells. In human immunodeficiency virus (HIV) subjects receiving PI-based treatment, an impressive decrease in the amount of HIV-associated cancers, unconnected to viral burden or CD4 amount was observed. Research has reported that PIs have influence on cancer proliferation, spread, and survival as an effect on endoplasmic reticulum stress, proteasome, NF- $\kappa \mathrm{B}$ and Akt signalling. Nelfinavir (NFV) is a nonpeptidic PI that functions by connecting to the catalytic site of the HIV protease, thus stopping the cleavage of viral polyprotein into complete, operative proteins that are fundamental for viral survival. NFV, currently not frequently employed for antiretroviral treatment, has demonstrated noteworthy off target effects in tumor patients with or without HIV disease. NFV appears to cause cell death in tumor cells by different mechanisms, which include necrosis, apoptosis and autophagy. In this review, data from preclinical research and clinical trials are reported and the mechanisms of action of NFV and their results in the treatment of hematologic malignancies, such as acute myeloid leukemia, chronic lymphoid leukemia, and diffuse large B cell lymphoma, and especially in patients with multiple myeloma are examined. In the future, experimental studies may help identify the role of NFV in cancer treatment and may promote the application of this drug into daily clinical practice.
\end{abstract}

Correspondence to: Professor A. Allegra, Division of Hematology, Department of Human Pathology in Adulthood and Childhood 'Gaetano Barresi', University of Messina, Via Consolare Valeria 1, I-98125 Messina, Italy

E-mail: aallegra@unime.it

Key words: HIV, protease inhibitors, nelfinavir, endoplasmic reticulum stress, proteasome, hematologic malignancies, multiple myeloma

\section{Contents}

1. Introduction: General considerations on protease inhibitors

2. Nelfinavir

3. Nelfinavir and cancer

4. Nelfinavir and haematological malignancies

5. Nelfinavir and multiple myeloma

6. Nelfinavir and its disadvantages

7. Future perspectives

8. Conclusions

1. Introduction: General considerations on protease inhibitors

Protease inhibitors (PIs) inhibit human immunodeficiency virus (HIV)-1 and HIV-2 proteases, impeding viral replication and liberation of viral elements from infected cells. The mechanism of action of PIs involves competitive binding to the enzyme. PIs were designed to halt the development of the HIV virion, by impeding cleavage of polyproteins by the viral aspartyl protease into their operational layout. Since 1995, by employing the HIV protease crystal layout, various small inhibitors have been constructed for HIV therapy. To date, numerous PIs have been produced including ritonavir, amprenavir, lopinavir, ritonavir, atazanavir, indinavir, darunavir, fosamprenavir and tipranavir. Their use has caused a decrease in the mortality rate due to HIV infection, and a reduction in the prevalence of opportunistic infections (1). In fact, with the use of PIs and of HIV reverse transcriptase inhibitors the era of highly active antiretroviral treatment (HAART) started, which is now the main therapy in HIV infection. Moreover, in HIV subjects receiving PI-based treatment, an impressive decrease in the amount of HIV-associated cancers, unconnected to the viral burden or CD4 amount, has been observed. This has paved the way for a series of studies aimed at evaluating the effects of PIs on neoplastic diseases. It has been therefore demonstrated that numerous PIs have consequences on cancer proliferation, spread and outcome. This is possibly due to actions on endoplasmic reticulum (ER) stress, the proteasome, NF- $k B$ and Akt signaling $(2,3)$.

Employing drugs used for the treatment of infectious diseases to cure tumors has been noted in several previous cases, such as fludarabine and tetracycline, which have demonstrated action 
on women with breast cancer (4). The possible use of anti-HIV drugs against cancer is also not new. Research has demonstrated that PIs display anticancer action which is independent from their capacity to interfere with the HIV protease. Ikeoze et al demonstrated that ritonavir, indinavir and saquinavir mediated a decrease in the growth and differentiation of HL-60 and NB4 myeloid leukemia cells (5). Other studies have shown that PIs can reduce the growth of Kaposi sarcoma, urological cancer cells and pheocromocytoma cells (5-8).

Notwithstanding their partial similarity with the HIV protease, cellular proteases appear to be the main target of PIs that are responsible for their anticancer action. PIs particularly act on the proteasome and extracellular matrix metalloproteases (1). Nevertheless, several of the supplementary actions of PIs have been demonstrated. PIs can reduce angiogenesis via a reduction in the phosphoinositide 3-kinase (PI3K)/Akt pathway, which regulates the production of vascular endothelial growth factor (VEGF) $(9,10)$, increase apoptosis in cancer cells by inhibition of STAT3 and c-Src. Moreover, PIs may block NF- $\kappa \mathrm{B}$ activation via a reduction in proteasomal degradation of $\operatorname{I} \alpha \mathrm{B}(6,11-14)$. However, the actions appear to be cell type-dependent; for instance, ritonavir may be protective against cell death in normal T cells (15).

A fundamental work by Gills et al demonstrated that PIs displayed an effect against all 60 cell lines in the NCI60 panel and the authors reported several possible mechanisms of action of PIs against tumor cells (16).

\section{Nelfinavir}

In March 1997, the Food and Drug Administration approved nelfinavir (NFV) for HIV treatment. NFV is an orally available drug used against HIV-1 and HIV-22 (17) (Fig. 1). NFV is a nonpeptidic PI that works by binding to the catalytic site of the HIV protease, thus impeding the maturation of viral polyprotein precursors into operational proteins that are indispensable for viral proliferation. NFV is present in tablets of 250 and $625 \mathrm{mg}$ or as an oral suspension powder. The suggested dose of NFV for adult patients is $1,250 \mathrm{mg}$ twice or $750 \mathrm{mg}$ three times a day (17).

Currently, NFV is infrequently employed for antiretroviral therapy, as it is being replaced by second-generation HIV PIs but has demonstrated beneficial effects in tumor patients with or without HIV infection (Fig. 2).

A previous study demonstrated that PIs have action against cancer cells, with NFV being the most powerful among the drugs tested (16). A complete computational study of protein interactions has discovered 92 predicted cellular targets of NFV, among which there were 7 with the highest binding affinities and they were aspartyl proteases (18). The residual targets were growth factor receptors that regulate $\mathrm{NF}-\kappa \mathrm{B}, \mathrm{Akt}$ and other signaling molecules (19).

Indeed, NFV appears to be the most effective inhibitor of Akt, even though this differs by cellular type (20). In rapamycin-resistant diffuse large $\mathrm{B}$ cell lymphoma cell lines in which Akt was upregulated, the use of NFV with Akt inhibitor MK-2206 resulted in increased cytotoxicity $(21,22)$.

A different mechanism through which NFV could express its antineoplastic action could be its action on angiogenesis. NFV can block angiogenesis via the downregulation of
PI3K/Akt, which regulates the expression of VEGF and other elements implicated in cancer neovascularization (10). However, the concentration of Akt does not constantly correlate with the anticancer action, and in some experimental models NFV paradoxically stimulated Akt (23). This may result from a reduction in growth factors or an increase in endoplasmic reticulum (ER) stress. In fact, the most relevant anticancer action of NFV is due to ER stress and unfolded protein response (UPR) which may be one of the means resulting in cell death (24). NFV blocks the proteases S1P and S2P that are implicated in SREBP-1 maturation and other proteases essential for protein folding in ER (25).

Shim et al and Srirangam et al studied different breast cancer cell lines and demonstrated that NFV reduced the growth of human epidermal growth factor receptor 2 (HER2)-positive breast cancer cells when compared to HER2-negative cells. In HER2-positive breast cancer cells, NFV provoked a degradation of HER 2 and Akt by blocking their connection with heath shock protein 90 (HSP90) $(26,27)$.

\section{Nelfinavir and cancer}

As stated above, NFV promotes cell death in tumor cells by different mechanisms, including necrosis, apoptosis and autophagy $(16,28)$. The accumulation of misfolded proteins could be the main mechanism of action of NFV in glioma, ovarian cancer cells, and lung cancer (28-30).

In breast cancer cells, tamoxifen increases the antitumor action of NFV. This synergic effect was unconnected to the estrogen receptor status so that the combination of NFV and tamoxifen may be useful even in subjects with no hormone responsive tumors (31) (Table I).

In a different study, the proteasome inhibitor bortezomib and NFV were used in experiments with human cervical cancer cells. Both substances provoked cell cycle arrest in tumor cells. An increase in the molecular chaperone BiP and in cell stress marker ATF3 suggested the induction of UPR as the main mechanism of cell death in tumor cells. NFV showed no actions on proteasomal activity in the tumor cells. Even when NFV and bortezomib were active on cisplatin-resistant cervical cancer cells, neither of the two substances provoked a sensitization to cisplatin therapy. Instead, both drugs augmented the effectiveness of an apoptosis-inducing TRAIL receptor antibody (32).

In head and neck tumors, NFV promoted a reduction in Akt and radiosensitization (33), while in adenoid cystic cancer, NFV reduced Akt and MAPK (34), and decreased oral cell growth, including normal keratinocytes and squamous cancer cells (35).

Finally, there is evidence that NFV is able to act on pancreatic tumors (36), while data have demonstrated the ability of NFV to sensitize tumor cells to chemoradiotherapy (36).

\section{Nelfinavir and haematological malignancies}

Several studies have demonstrated the possibility of NFV to take action not only on solid neoplasms but also on haematological malignancies (Table II) such as acute myeloid leukemia (AML).

Brüning et al assessed the action of NFV on leukemia cells and non-malignant bone marrow-derived cells. At a dosage of $9 \mu \mathrm{g} / \mathrm{ml}$, NFV caused $90 \%$ cell death of IM9, HL60, and Jurkat cells. At similar levels, less than $10 \%$ of non-malignant bone 
marrow-derived cells displayed NFV-provoked cell damage. $\mathrm{NFV}$-provoked death of leukemia cells was preceded by an increase in caspases 3, 7 and 8. However, despite caspase activation, the increase in the antiapoptotic bcl-2 family member protein mcl-1 that followed the NFV treatment stabilized the mitochondrial membrane potential, causing mitochondrial-independent cell death. Reduction in mcl-1 expression using sorafenib increased NFV-induced apoptosis even at minor NFV levels but did not have supplementary negative actions on non-malignant bone marrow cells (37).

Similarly, NFV exhibited a cytotoxic effect against primary AML cells, stimulated PS-caused apoptosis, blocked AKT-phosphorylation and demonstrated synergistic cytotoxicity with carfilzomib and bortezomib at micromolar levels (38). NFV blocked intracellular proteasome activity, including $\beta 2$ proteasome activity that was not affected by bortezomib and carfilzomib (39).

The presence of NFV-caused cytotoxicity was also reported in pediatric leukemia cells. NFV was tested against pediatric leukemia cells by in vitro proliferation inhibition essays. Several substances were recognized to have a synergistic effect with NFV in its antileukemic activity such as AT101 (Bcl-2 family inhibitor), sunitinib (TK inhibitor), and JQ1 (BET inhibitor) (40).

NFV has also been shown to have a possible therapeutic action in lymphoproliferative disorders. NFV provokes moderate ER stress and autophagy in chronic lymphoid leukemia (CLL) cells. Remarkably, NFV did not cause direct cytotoxicity against CLL cells as a single drug. Nevertheless, co-treatment with NFV and chloroquine markedly provoked the direct death of CLL cells in vitro (41).

Diffuse large B cell lymphoma (DLBCL) is the most frequent type of Non-Hodgkin's lymphoma (NHL) (42). The mTOR pathway is constitutively stimulated in DLBCL, and blockage of mTOR is a possible treatment for DLBCL (43), although the response to mTOR inhibitors (mTORi) is approximately $30 \%$ in DLBCL (44) due to the onset of resistance to mTORi (45).

Petrich et al assessed DLBCL cell lines with differential resistance to the mTORi. Then the authors assessed NFV and MK-2006, chosen for their potential to synergize with rapamycin in DLBCL. Both substances demonstrated synergistic inhibition of cell viability in combination with rapamycin in DLBCL cell lines, and strongly inhibited targets of activated mTOR (21).

Another research study investigated the possibility that IPs may modify the kinetics of drugs employed in lymphoma treatment. Comprehensive pharmacokinetics and pharmacodynamic analysis were carried out in 19 NHL subjects during 38 cycles of chemotherapy: 19 cycles with CHOP and 19 CHOP + HAART. Highly active antiretroviral therapy (HAART) comprised NFV, saquinavir (SQV), and indinavir (IDV). No substantial actions of HAART on the pharmacokinetic values of doxorubicin (DOX) were described. Similarly, no differential action on DOX pharmacokinetics among NFV, SQV, and IDV was demonstrated (46).

\section{Nelfinavir and multiple myeloma}

The hematological pathology in which the effects of NFV have been most studied is represented by multiple myeloma (MM).
Table I. Studies demonstrating the effects of nelfinavir on cancer.

\begin{tabular}{|c|c|c|}
\hline Cancer cells & Actions & (Refs.) \\
\hline Breast cancer cells & $\begin{array}{l}\text { Synergic action with } \\
\text { tamoxifen }\end{array}$ & 31 \\
\hline Cervical cancer cells & Cell cycle arrest & 32 \\
\hline Head and neck tumor & Radiosensitization & 33 \\
\hline Adenoid cystic cancer & Reduced cell growth & 34 \\
\hline
\end{tabular}

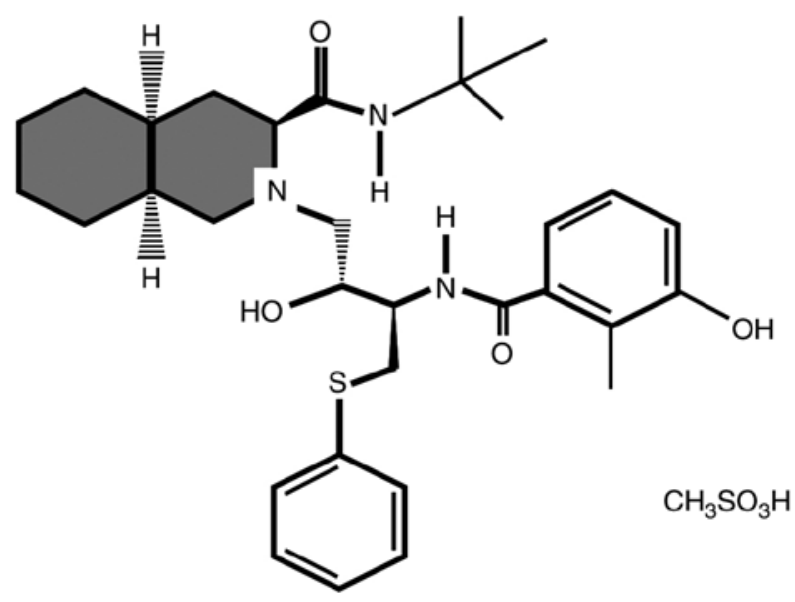

Figure 1. The chemical structure of nelfinavir.

Ikezoe et al demonstrated that NFV promoted suppression of proliferation and cell death of MM RPMI8226, U266, and ARH77 cell lines. This event occurred in association with a decrease in the antiapoptotic protein Mcl-1. Moreover, NFV suppressed the survival of isolated MM cells from subjects. However, NFV did not influence survival of normal bone marrow (BM)-derived cells and colony formation of myeloid committed stem cells (CFU-GM) from control subjects. Furthermore, the authors observed that NFV reduced interleukin-6 (IL-6)-stimulated phosphorylation of both signal transducer and activator of transcription 3 (STAT3) in MM cells and decreased basal and IL-6-stimulated STAT3/DNA binding activity (47).

A relevant aspect of NFV action is represented by the ability of PIs to act synergistically with the drugs used in the treatment of MM. It was demonstrated that NFV and bortezomib (BZ) synergistically increased proteotoxicity, reduced cell growth and provoked cell death in MM cells. The combination of the two drugs increased activating transcription factor (ATF)3 and CCAAT-enhancer binding protein homologous protein (CHOP), markers of ER stress, while their siRNA-mediated knockdown reduced cell death. Pre-treatment with cycloheximide (a protein synthesis inhibitor), reduced the concentrations of ubiquitinated proteins, CHOP and ATF3, indicating that reduction in protein synthesis augments cell survival by reducing proteotoxic stress. The use of NFV/BZ was found to reduce the proliferation of non-small cell lung carcinoma (NSCLC) xenografts, which was associated with the increase in markers of ER stress and cell death (48). 
Table II. Studies demonstrating the effects of nelfinavir on hematologic malignancies.

Tumor cell lines and patients

Effect

(Refs.)

Leukemia cells

Primary acute myeloid leukemia

Increased cell death

Pediatric leukemia cells

Increased apoptosis

Chronic lymphoid leukemia

Proliferation inhibition

Diffuse large B cell lymphoma cell lines

Increase of autophagy

Inhibition of cell viability

MM cell lines

Increased cell death

Phase I trial

Overcomes proteasome inhibition resistance in MM patients

60

Phase I/II trial in MM patients

Overcomes lenalidomide resistance in MM patients

66

Phase II trial in MM patients

ORR $65 \%$

61

MM, multiple myeloma; ORR, objective response rate.

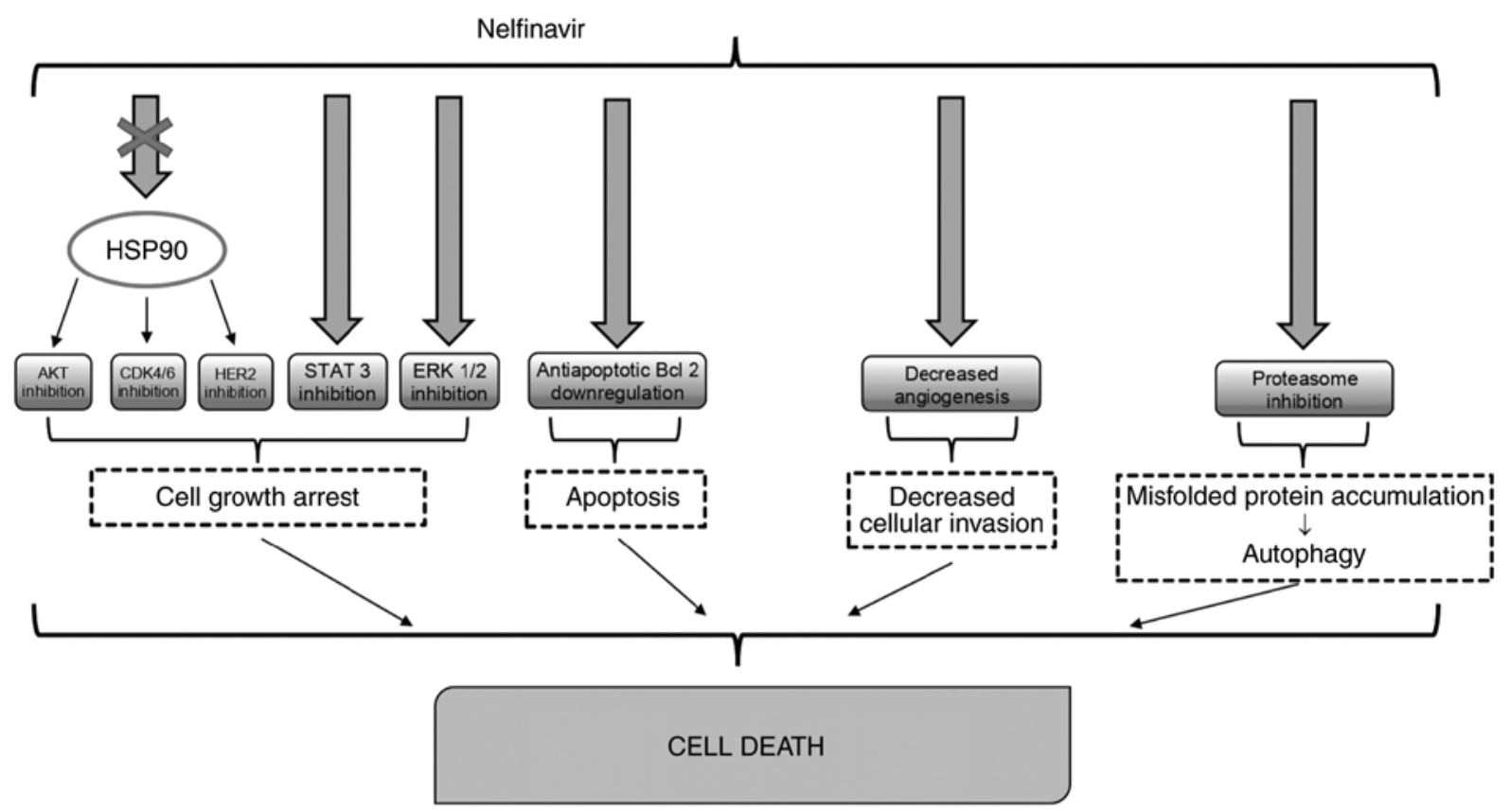

Figure 2. Possible actions of nelfinavir in neoplastic diseases. AKT, protein kinase B; CDK4/6, cell division protein kinase 4/6; HER2, human epidermal growth factor receptor 2; STAT3, signal transducer and activator of transcription 3; Bcl2, B-cell lymphoma 2.

Proteasome inhibitors are the mainstay of MM treatment. Nevertheless, certain MM patients acquire proteasome inhibitor resistance. It is well known that the proteasome inhibitor sensitivity of MM cells is controlled by UPR $(49,50)$, that avoids accumulation of altered proteins in the ER by operating on mRNA translation and protein destruction. This is controlled by ER-associated degradation machinery, with the proteasome as its rate-limiting terminal protease (51). Extreme activation of UPR causes apoptosis and this is the main mechanism of action of BZ in MM patients (52). The concentration of UPR pre-activation regulates the proteasome inhibitor-sensitivity of MM, so that an increase in UPR may overcome proteasome inhibitor resistance (53). Activation of UPR is started via inositol-requiring kinase 1 (IRE1) (54). Full plasma cell maturation requires UPR activation via the IRE1/XBP1 axis and causes a mature, proteasome inhibitor-sensitive MM cell type. On the contrary,
IRE1-/XBP1-MM cells are proteasome inhibitor-resistant and are increased in proteasome inhibitor-resistant MM subjects. However, while IRE1-targeting drugs are at an early stage of assessment (55), it has been demonstrated that NFV has UPR- and IRE1/XBP1-stimulating activity $(24,56)$. This activity may interest interference with UPR-stimulating proteases (57), the AKT pathway (58) and the proteasome (59). It is able to re-sensitize proteasome inhibitor-resistant MM cells at low micromolar levels (38).

In addition to preclinical studies, numerous clinical trials have attempted to demonstrate the efficacy of NFV in patients with MM. In a phase I trial (SAKK 65/08), the authors demonstrated that NFV blocked proteasome activity and increased the amount of proteins correlated to UPR in peripheral blood mononuclear cells. Contemporary use of NFV with BZ further stimulated UPR and overwhelmed proteasome inhibitor resistance (60). 
In another study, the authors performed a phase 2 trial (SAKK 39/13) to study the effects and safety of NFV in MM refractory subjects to proteasome inhibitors and previously treated with immunomodulatory drugs. The protocol provided for administration of NFV 2,500 mg on days 1-14 twice daily; bortezomib $1.3 \mathrm{mg} / \mathrm{m}^{2}$ i.v./subcutaneously on days $1,4,8$ and 11; and dexamethasone $20 \mathrm{mg}$ orally on days 1-2, 4-5, 8-9 and 11-12 for up to six 21-day cycles. The results of the study were remarkable. Patients were heavily pre-treated, but ORR was $65 \%$, a rate comparable to the one reported in first-line BZ-naïve subjects. Moreover, it is possible that clinical advantage was underestimated as the treatment was administered only for 4.2 months (61).

NFV has proteasome-blocking action at high levels (20-40 $\mu \mathrm{M}$ ) in vitro (62), but peak NFV levels at the $2 \times 1,875 \mathrm{mg}$ dose are in the $15 \mu \mathrm{M}$ range in treated subjects (60). Besse et al conjectured that adjoining lenalidomide to NFV therapy may augment intracellular NFV levels necessarily to cause the pan-proteasome-blocking action seen with high levels of NFV. Both NFV and lenalidomide are substrates of MDR-1 type drug efflux pumps (63); thus, competition of the two substances for the MDR-1 drug pump may reduce the efflux of NFV. Similarly, NFV may augment the efficacy of the treatment by increasing intracellular lenalidomide levels within myeloma cells (63). Similar considerations can also be made for the simultaneous administration of NFV with carfilzomib, a different proteasome inhibitor $(64,65)$.

A phase I/II trial evaluated whether adjoining NFV to lenalidomide-dexamethasone can overcome lenalidomide resistance in MM patients. Twenty-nine subjects were studied (lenalidomide-BZ double-refractory 34\%). They were treated with four cycles of NFV 2,500 mg/day with lenalidomide $25 \mathrm{mg}$ days 1-21 and dexamethasone (40/20 mg days 1, 8, 15 and 22). It was shown that a minor response was attained in $55 \%$ of patients, while a partial response was achieved in 9 patients $(31 \%)$. Median overall survival was 21.6 months. Peripheral blood mononuclear cells exhibited a $45 \%$ (95\% CI, 40-51\%) decrease in total proteasome activity and substantial increase of UPR and autophagy. Thus, NFV/lenalidomide/dexamethasone appears to be an active oral treatment for lenalidomide-refractory MM (66).

\section{Nelfinavir and its disadvantages}

Severe adverse effects of PIs are infrequent with the exclusion of diarrhea when employed at high dosages. Nevertheless, there are other unfavorable side events with PIs, such as insulin resistance, hyperlipidemia and lypodystrophy. The main factor underlying these side events is the suppression of the breakdown of sterol regulatory element binding proteins (SREBP) in the liver and adipose tissues causing an increased cholesterol and fatty acid biosynthesis. SREBP storage in adipose tissue provokes lipodystrophy. Moreover, PIs reduce proteasome-mediated breakdown of lipoprotein (apo) B, causing an increase in the production of triglyceride. Finally, NFV also reduces storage of the glucose transporter GLUT-4 in adipose tissue. This may promote the onset of insulin resistance and diabetes (67).

Moreover, an increase in serum aminotransferase may occur in subjects receiving NFV. Considerable increase in serum aminotransferase levels ( $>5$ times) is present in 3-10\% of subjects.
This increase is generally asymptomatic and self-limited and does not require suspension of the drug. Hepatomegaly and hepatic steatosis are direct effects of the metabolic changes reported above (68). Clinical features of hypersensitivity such as rash, fever, of eosinophilia can arise as autoantibody formation but these events are not very noticeable. Finally, it was reported that myelosuppression is more common in subjects treated with chemotherapy and HAART combination (69).

However, despite the substantially good tolerability of treatment with NFV, some issues must be solved. Although NFV has pro-apoptotic activity on tumor cells, an increase was reported in the antiapoptotic mitochondrial membrane protein mcl-1 able to increase phosphorylation of ERK1/2 (extracellular signal-regulated kinases 1/2) (70). Upregulation of ERK is able to reduce cell death. This condition can be solved with the administration of sorafenib $(37,70)$.

Moreover, in spite of the antitumor action of NFV, this drug does not decrease the risk of tumor onset in HIV patients and also causes a reduction in immunological functions, altering the differentiation of monocytes into dendritic cells $(71,72)$. Finally, although the results from numerous studies demonstrate that the combination of HAART with chemotherapy improves prognosis, many uncertainties exist on the choice of the best combination of chemotherapy and PIs. Overlapping toxicities have been reported with combination treatment, and there is a possible risk for pharmacokinetic associations between chemotherapy and PIs (73).

\section{Future perspectives}

Although the use of NFV has given encouraging results in in vitro and in vivo studies, even better results could be achieved by using drug combinations. Akt activation plays a main role in the tumor phenotype (74). At present there are no substances able to inhibit this protein with a convenient safety profile. The anti-Akt action of NFV can be increased by simultaneous mTOR blockage which provokes a synergistic cytotoxicity (21). This may be since mTOR inhibition without Akt blockage removes a negative biofeedback loop on Akt, causing increased phosphorylation of Akt $(75,76)$. The negative bio-feedback loop on Akt must be solved to achieve appropriate results. NFV could be useful to obtain better results when used with mTORi.

Numerous other substances have been identified as possible synergists with NFV. NFV increases anti-malarial activity of artemisinin in vitro on Plasmodium falciparum, but artemisinin also has antitumor action (77). Several studies have tried to evaluate whether the simultaneous administration of artemisinin and NFV could enhance the antineoplastic action of the two substances. A research study employed NFV and artemisinin, in an experimental protocol (CUSP 9) for the therapy of relapsed glioblastoma. The combination was reported to postpone glioblastoma spread (78).

Experimental tests are however necessary to verify the possibility that the use of NFV with other drugs such as celecoxib or chloroquine, may be effective for the treatment of neoplasms. In fact, the cancer cell killing capacity of NFV can be increased with different ER stressors such as celecoxib (79); perillyl alcohol is another stress factor that has been employed using this rationale (80). 
Hydroxicloroquine and chloroquine are autophagy inhibitors and may also operate synergistically with NFV, decreasing autophagy and augmenting apoptosis $(41,81,82)$.

\section{Conclusions}

Drug repositioning leads to the identification of new indications for current drugs and the use of the newly recognized medicines to therapy of diseases other than the drug's intended target. Even though the exact molecular target of NFV is still to be identified, its efficacy and safety are well known. All data reported in this review support the hypothesis that NFV is a useful means of integration in cancer treatment. In the future, it should be evaluated in combination with chemotherapy in the design of new protocols. Indeed, it is fundamental to establish the most appropriate associations, dosing and timing of NFV administration in patients with MM or other hematological diseases. In fact, concurrent therapy with PIs is not without drug interactions. As such, clinical decisions regarding therapy should be carefully evaluated, and dose adjustments must be made to reduce the risk for adverse outcomes and disease progression. Moreover, new PIs are being created with better anticancer activity and further development of new PIs with stronger anticancer activity will be realized in the future.

Despite the above, research for the use of antivirals in the treatment of hematologic neoplasias and in particular MM is ongoing. In fact, notwithstanding recent advanced therapy opportunities such as proteasome inhibitors, histone deacetylase inhibitors, immunomodulatory drugs and immunotherapy, and myeloma-targeted antibodies (83-87), MM is still judged as an incurable disease.

\section{Acknowledgements}

Not applicable.

\section{Funding}

No funding was received.

\section{Availability of data and materials}

All information was cited by relevant references listed in the Review.

\section{Authors' contributions}

Conceptualization of the review was carried out by AA and CM. Curation of the data was conducted by VI, AGA, MP and NP. Writing of the original draft was undertaken by AA. Writing of the review and editing were carried out by AA and CM. All authors read and approved the final manuscript.

\section{Ethics approval and consent to participate}

Not applicable.

\section{Patient consent for publication}

Not applicable.

\section{Competing interest}

The authors state that they have no competing interests.

\section{Authors' information}

Alessandro Allegra, Orcid: 0000-0001-6156-8239.

\section{References}

1. Gantt S, Casper C and Ambinder RF: Insights into the broad cellular effects of nelfinavir and the HIV protease inhibitors supporting their role in cancer treatment and prevention. Curr Opin Oncol 25: 495-502, 2013.

2. Niehues T, Horneff G, Megahed M, Schroten H and Wahn V: Complete regression of AIDS-related Kaposi's sarcoma in a child treated with highly active antiretroviral therapy. AIDS 13: 1148-1149, 1999.

3. Sgadari C, Monini P, Barillari G and Ensoli B: Use of HIV protease inhibitors to block Kaposi's sarcoma and tumour growth. Lancet Oncol 4: 537-547, 2003.

4. Xing F, Liu Y, Wu SY, Wu K, Sharma S, Mo YY, Feng J, Sanders S, Jin G, Singh R, et al: Loss of XIST in breast cancer activates MSN-c-Met and reprograms microglia via Exosomal miRNA to promote brain metastasis. Cancer Res 78: 4316-4330, 2018.

5. Ikezoe T, Daar ES, Hisatake J, Taguchi H and Koeffler HP: HIV-1 protease inhibitors decrease proliferation and induce differentiation of human myelocytic leukemia cells. Blood 96:3553-3559, 2000.

6. Pati S, Pelser CB, Dufraine J, Bryant JL, Reitz MS Jr and Weichold FF: Antitumorigenic effects of HIV protease inhibitor ritonavir: Inhibition of Kaposi sarcoma. Blood 99: 3771-3779, 2002.

7. Okubo K, Isono M, Asano T and Sato A: Lopinavir-ritonavir combination induces endoplasmic reticulum stress and kills urological cancer cells. Anticancer Res 39: 5891-5901, 2019.

8. Lu M, Dong H, Bao D, Liu B and Liu H: Tenofovir disoproxil fumarate induces pheochromocytoma cells apoptosis. Eur J Pharmacol 844: 139-144, 2019.

9. Esposito V, Verdina A, Manente L, Spugnini EP, Viglietti R, Parrella R, Pagliano P, Parrella G, Galati R, De Luca A, et al: Amprenavir inhibits the migration in human hepatocarcinoma cell and the growth of xenografts. J Cell Physiol 228: 640-645, 2013.

10. Pore N, Gupta AK, Cerniglia GJ and Maity A: HIV protease inhibitors decrease VEGF/HIF-1alpha expression and angiogenesis in glioblastoma cells. Neoplasia 8: 889-895, 2006.

11. Sun L, Niu L, Zhu X, Hao J, Wang P and Wang H: Antitumour effects of a protease inhibitor, nelfinavir, in hepatocellular carcinoma cancer cells. J Chemother 24: 161-166, 2012.

12. Dewan MZ, Uchihara JN, Terashima K, Honda M, Sata T, Ito M, Fujii N, Uozumi K, Tsukasaki K, Tomonaga M, et al: Efficient intervention of growth and infiltration of primary adult T-cell leukemia cells by an HIV protease inhibitor, ritonavir. Blood 107: 716-724, 2006

13. Srirangam A,Milani M,Mitra R,GuoZ, RodriguezM,KathuriaH, Fukuda S, Rizzardi A, Schmechel S, Skalnik DG, et al: The human immunodeficiency virus protease inhibitor ritonavir inhibits lung cancer cells, in part, by inhibition of survivin. J Thorac Oncol 6: 661-670, 2011.

14. Timeus F, Crescenzio N, Doria A, Foglia L, Pagliano S, Ricotti E, Fagioli F, Tovo PA and Cordero di Montezemolo L: In vitro anti-neuroblastoma activity of saquinavir and its association with imatinib. Oncol Rep 27: 734-740, 2012.

15. Weichold FF, Bryant JL, Pati S, Barabitskaya O, Gallo RC and Reitz MS Jr: HIV-1 protease inhibitor ritonavir modulates susceptibility to apoptosis of uninfected T cells. J Hum Virol 2: 261-269, 1999.

16. Gills JJ, Lopiccolo J, Tsurutani J, Shoemaker RH, Best CJ, Abu-Asab MS, Borojerdi J, Warfel NA, Gardner ER, Danish M, et al: Nelfinavir, A lead HIV protease inhibitor, is a broad-spectrum, anticancer agent that induces endoplasmic reticulum stress, autophagy, and apoptosis in vitro and in vivo. Clin Cancer Res 13: 5183-5194, 2007.

17. National Institute of Diabetes and Digestive and Kidney Diseases. Protease Inhibitors (HIV). LiverTox: Clinical and research information on drug-induced liver injury [Internet]. PMID: 31644200. Bethesda (MD). Sep 1, 2012-2017. 
18. Xie L, Evangelidis T, Xie L and Bourne PE: Drug discovery using chemical systems biology: Weak inhibition of multiple kinases may contribute to the anti-cancer effect of nelfinavir. PLoS Comput Biol 7: e1002037, 2011.

19. Gills JJ, Lopiccolo J and Dennis PA: Nelfinavir, a new anti-cancer drug with pleiotropic effects and many paths to autophagy. Autophagy 4: 107-109, 2008.

20. Kraus M, Bader J, Overkleeft $H$ and Driessen C: Nelfinavir augments proteasome inhibition by bortezomib in myeloma cells and overcomes bortezomib and carfilzomib resistance. Blood Cancer J 3: e103, 2013.

21. Petrich AM, Leshchenko V, Kuo PY, Xia B, Thirukonda VK, Ulahannan N, Gordon S, Fazzari MJ, Ye BH, Sparano JA and Parekh S: Akt inhibitors MK-2206 and nelfinavir overcome mTOR inhibitor resistance in diffuse large B-cell lymphoma. Clin Cancer Res 18: 2534-2544, 2012.

22. Plastaras JP, Vapiwala N, Ahmed MS, Gudonis D, Cerniglia GJ, Feldman MD, Frank I and Gupta AK: Validation and toxicity of PI3K/Akt pathway inhibition by HIV protease inhibitors in humans. Cancer Biol Ther 7: 628-635, 2008.

23. Jiang W, Mikochik PJ, Ra JH, Lei H, Flaherty KT, Winkler JD and Spitz FR: HIV protease inhibitor nelfinavir inhibits growth of human melanoma cells by induction of cell cycle arrest. Cancer Res 67: 1221-1227, 2007.

24. Bernstein WB and Dennis PA: Repositioning HIV protease inhibitors as cancer therapeutics. Curr Opin HIV AIDS 3: 666-675, 2008

25. Guan M, Fousek K and Chow WA: Nelfinavir inhibits regulated intramembrane proteolysis of sterol regulatory element binding protein-1 and activating transcription factor 6 in castration-resistant prostate cancer. FEBS J 279: 2399-2411, 2012.

26. Shim JS, Rao R, Beebe K, Neckers L, Han I, Nahta R and Liu JO: Selective inhibition of HER2-positive breast cancer cells by the HIV protease inhibitor nelfinavir. J Natl Cancer Inst 104: 1576-1590, 2012

27. Srirangam A, Mitra R, Wang M, Gorski JC, Badve S, Baldridge L, Hamilton J, Kishimoto H, Hawes J, Li L, et al: Effects of HIV protease inhibitor ritonavir on Akt-regulated cell proliferation in breast cancer. Clin Cancer Res 12: 1883-1896, 2006.

28. Pyrko P, Kardosh A, Wang W, Xiong W, Schönthal AH and Chen TC: HIV-1 protease inhibitors nelfinavir and atazanavir induce malignant glioma death by triggering endoplasmic reticulum stress. Cancer Res 67: 10920-10928, 2007.

29. Peñaranda Fajardo NM, Meijer C and Kruyt FA: The endoplasmic reticulum stress/unfolded protein response in gliomagenesis, tumor progression and as a therapeutic target in glioblastoma. Biochem Pharmacol 118: 1-8, 2016.

30. Brüning A, Burger P, Vogel M, Rahmeh M, Gingelmaiers A, Friese K, Lenhard $M$ and Burges A: Nelfinavir induces the unfolded protein response in ovarian cancer cells, resulting in ER vacuolization, cell cycle retardation and apoptosis. Cancer Biol Ther 8: 226-232, 2009.

31. Brüning A, Friese K, Burges A and Mylonas I: Tamoxifen enhances the cytotoxic effects of nelfinavir in breast cancer cells. Breast Cancer Res 12: R45, 2010.

32. Bruning A, Vogel M, Mylonas I, Friese $\mathrm{K}$ and Burges A: Bortezomib targets the caspase-like proteasome activity in cervical cancer cells, triggering apoptosis that can be enhanced by nelfinavir. Curr Cancer Drug Targets 11: 799-809, 2011.

33. Gupta AK, Lee JH, Wilke WW, Quon H, Smith G, Maity A, Buatti JM and Spitz DR: Radiation response in two HPV-infected head-and-neck cancer cell lines in comparison to a non-HPV-infected cell line and relationship to signaling through AKT. Int J Radiat Oncol Biol Phys 74: 928-933, 2009.

34. Gupta AK, Wilke WW, Taylor EN, Bodeker KL, Hoffman HT, Milhem MM, Buatti JM and Robinson RA: Signaling pathways in adenoid cystic cancers: Implications for treatment. Cancer Biol Ther 8: 1947-1951, 2009.

35. Danaher RJ, Wang C, Roland AT, Kaetzel CS, Greenberg RN and Miller CS: HIV protease inhibitors block oral epithelial cell DNA synthesis. Arch Oral Biol 55: 95-100, 2010.

36. Kimple RJ, Vaseva AV, Cox AD, Baerman KM, Calvo BF, Tepper JE, Shields JM and Sartor CI: Radiosensitization of epidermal growth factor receptor/HER2-positive pancreatic cancer is mediated by inhibition of Akt independent of ras mutational status. Clin Cancer Res 16: 912-923, 2010.

37. Brüning A, Rahmeh M, Gingelmaier A and Friese K: The mitochondria-independent cytotoxic effect of nelfinavir on leukemia cells can be enhanced by sorafenib-mediated mcl-1 downregulation and mitochondrial membrane destabilization. Mol Cancer 9: $19,2010$.
38. Kraus M, Müller-Ide H, Rückrich T, Bader J, Overkleeft H and Driessen C: Ritonavir, nelfinavir, saquinavir and lopinavir induce proteotoxic stress in acute myeloid leukemia cells and sensitize them for proteasome inhibitor treatment at low micromolar drug concentrations. Leuk Res 38: 383-392, 2014.

39. Allegra A, Alonci A, Gerace D, Russo S, Innao V, Calabrò L and Musolino C: New orally active proteasome inhibitors in multiple myeloma. Leuk Res 38: 1-9, 2014.

40. Meier-Stephenson V, Riemer J and Narendran A: The HIV protease inhibitor, nelfinavir, as a novel therapeutic approach for the treatment of refractory pediatric leukemia. Onco Targets Ther 10: 2581-2593, 2017.

41. Mahoney E, Maddocks K, Flynn J, Jones J, Cole SL, Zhang X, Byrd JC and Johnson AJ: Identification of endoplasmic reticulum stress-inducing agents by antagonizing autophagy: A new potential strategy for identification of anti-cancer therapeutics in B-cell malignancies. Leuk Lymphoma 54: 2685-2692, 2013.

42. Falduto A, Cimino F, Speciale A, Musolino C, Gangemi S, Saija A and Allegra A: How gene polymorphisms can influence clinical response and toxicity following R-CHOP therapy in patients with diffuse large B cell lymphoma. Blood Rev 31: 235-249, 2017.

43. Hess G, Smith SM, Berkenblit A and Coiffier B: Temsirolimus in mantle cell lymphoma and other non-Hodgkin lymphoma subtypes. Semin Oncol 36 (Suppl 3): S37-S45, 2009.

44. Smith SM, van Besien K, Karrison T, Dancey J, McLaughlin P, Younes A, Smith S, Stiff P, Lester E, Modi S, et al: Temsirolimus has activity in non-mantle cell non-Hodgkin's lymphoma subtypes: The University of Chicago phase II consortium. J Clin Oncol 28: 4740-4746, 2010

45. Witzig TE, Reeder CB, LaPlant BR, Gupta M, Johnston PB, Micallef IN, Porrata LF, Ansell SM, Colgan JP, Jacobsen ED, et al: A phase II trial of the oral mTOR inhibitor everolimus in relapsed aggressive lymphoma. Leukemia 25: 341-347, 2011.

46. Toffoli G, Corona G, Cattarossi G, Boiocchi M, Di Gennaro G, Tirelli U and Vaccher E: Effect of highly active antiretroviral therapy (HAART) on pharmacokinetics and pharmacodynamics of doxorubicin in patients with HIV-associated non-Hodgkin's lymphoma. Ann Oncol 15: 1805-1809, 2004.

47. Ikezoe T, Saito T, Bandobashi K, Yang Y, Koeffler HP and Taguchi I: HIV-1 protease inhibitor induces growth arrest and apoptosis of human multiple myeloma cells via inactivation of signal transducer and activator of transcription 3 and extracellular signal-regulated kinase 1/2. Mol Cancer Ther 3: 473-479, 2004.

48. Kawabata S, Gills JJ, Mercado-Matos JR, LoPiccolo J, Wilson III W, Hollander MC and Dennis PA: Synergistic effects of nelfinavir and bortezomib on proteotoxic death of NSCLC and multiple myeloma cells. Cell Death and Disease 3: e353, 2012.

49. Leung-Hagesteijn C, Erdmann N, Cheung G, Keats JJ, Stewart AK, Reece DE, Chung KC and Tiedemann RE: Xbpls-negative tumor B cells and pre-plasmablasts mediate therapeutic proteasome inhibitor resistance in multiple myeloma. Cancer Cell 24: 289-304, 2013.

50. Neznanov N, Komarov AP, Neznanova L, Stanhope-Baker P and Gudkov AV: Proteotoxic stress targeted therapy (PSTT): Induction of protein misfolding enhances the antitumor effect of the proteasome inhibitor bortezomib. Oncotarget 2: 209-221, 2011.

51. Mayor T: Navigating the ERAD interaction network. Nat Cell Biol 14: 46-47, 2011.

52. Obeng EA, Carlson LM, Gutman DM, Harrington WJ Jr, Lee KP and Boise LH: Proteasome inhibitors induce a terminal unfolded protein response in multiple myeloma cells. Blood 107: 4907-4916, 2006

53. Ling SC, Lau EK, Al-Shabeeb A, Nikolic A, Catalano A, Iland $\mathrm{H}$, Horvath N, Ho PJ, Harrison S, Fleming S, et al: Response of myeloma to the proteasome inhibitor bortezomib is correlated with the unfolded protein response regulator XBP-1. Haematologica 97: 64-72, 2012

54. Reimold AM, Iwakoshi NN, Manis J, Vallabhajosyula P, Szomolanyi-Tsuda E, Gravallese EM, Friend D, Grusby MJ, Alt $\mathrm{F}$ and Glimcher LH: Plasma cell differentiation requires the transcription factor XBP-1. Nature 412: 300-307, 2001.

55. Papandreou I, Denko NC, Olson M, Van Melckebeke H, Lust S, Tam A, Solow-Cordero DE, Bouley DM, Offner F, Niwa M and Koong AC: Identification of an Irelalpha endonuclease specific inhibitor with cytotoxic activity against human multiple myeloma. Blood 117: 1311-1314, 2011.

56. Chow WA, Jiang $\mathrm{C}$ and Guan M: Anti-HIV drugs for cancer therapeutics: Back to the future? Lancet Oncol 10: 61-71, 2009. 
57. Guan M, Fousek K, Jiang C, Guo S, Synold T, Xi B, Shih CC and Chow WA: Nelfinavir induces liposarcoma apoptosis through inhibition of regulated intramembrane proteolysis of SREBP-1 and ATF6. Clin Cancer Res 17: 1796-1806, 2011

58. Yang Y, Ikezoe T, Nishioka C, Bandobashi K, Takeuchi $T$, Adachi Y, Kobayashi M, Takeuchi S, Koeffler HP and Taguchi H: $\mathrm{NFV}$, an HIV-1 protease inhibitor, induces growth arrest, reduced Akt signalling, apoptosis and docetaxel sensitisation in NSCLC cell lines. Br J Cancer 95: 1653-1662, 2006.

59. Bono C, Karlin L, Harel S, Mouly E, Labaume S, Galicier L, Apcher S, Sauvageon H, Fermand JP, Bories JC and Arnulf B: The human immunodeficiency virus-1 protease inhibitor nelfinavir impairs proteasome activity and inhibits the proliferation of multiple myeloma cells in vitro and in vivo. Haematologica 97: 1101-1109, 2012.

60. Driessen C, Kraus M, Joerger M, Rosing H, Bader J, Hitz F, Berset C, Xyrafas A, Hawle H, Berthod G, et al: Treatment with the HIV protease inhibitor nelfinavir triggers the unfolded protein response and may overcome proteasome inhibitor resistance of multiple myeloma in combination with bortezomib: A phase I trial (SAKK 65/08). Haematologica 101: 346-355, 2016.

61. Driessen C, Müller R, Novak U, Cantoni N, Betticher D, Mach N Rüfer A, Mey U, Samaras P, Ribi K, et al: Promising activity of nelfinavir-bortezomib-dexamethasone in proteasome inhibitor-refractory multiple myeloma. Blood 132: 2097-2100, 2018.

62. Kraus M, Malenke E, Gogel J, Müller H, Rückrich T, Overkleeft H, Ovaa H, Koscielniak E, Hartmann JT and Driessen C: Ritonavir induces endoplasmic reticulum stress and sensitizes sarcoma cells toward bortezomib-induced apoptosis. Mol Cancer Ther 7: 1940-1948, 2008.

63. Besse A, Stolze SC, Rasche L, Weinhold N, Morgan GJ, Kraus M, Bader J, Overkleeft HS, Besse L and Driessen C: Carfilzomib resistance due to $\mathrm{ABCB} 1 / \mathrm{MDR} 1$ overexpression is overcome by nelfinavir and lopinavir in multiple myeloma. Leukemia 32 391-401, 2018.

64. Besse A, Besse L, Kraus M, Mendez-Lopez M, Bader J, Xin BT, de Bruin G, Maurits E, Overkleeft HS and Driessen C: Proteasome inhibition in multiple myeloma: Head-to-head comparison of currently available proteasome inhibitors. Cell Chem Biol 26: 340-351.e3, 2019.

65. Hawley TS, Riz I, Yang W, Wakabayashi Y, Depalma L, Chang YT, Peng W, Zhu J and Hawley RG: Identification of an ABCB1 (P-glycoprotein)-positive carfilzomib-resistant myeloma subpopulation by the pluripotent stem cell fluorescent dye CDy1. Am J Hematol 88: 265-272, 2013.

66. Hitz F, Kraus M, Pabst T, Hess D, Besse L, Silzle T, Novak U, Seipel K, Rondeau S, Stüdeli S, et al: Nelfinavir and lenalidomide/dexamethasone in patients with lenalidomide-refractory multiple myeloma. A phase I/II Trial (SAKK 39/10). Blood Cancer J 9: 70, 2019.

67. Hui DY: Effects of HIV protease inhibitor therapy on lipid metabolism. Prog Lipid Res 42: 81-92, 2003.

68. Riddle TM, Kuhel DG, Woollett LA, Fichtenbaum CJ and Hui DY: HIV protease inhibitor induces fatty acid and sterol biosynthesis in liver and adipose tissues due to the accumulation of activated sterol regulatory element-binding proteins in the nucleus. J Biol Chem 276: 37514-37519, 2001.

69. Orem J, Fu P, Ness A, Mwanda WO and Remick SC: Oral combination chemotherapy in the treatment of AIDS-associated Hodgkin's disease. East Afr Med J 82 (Suppl. 9): S144-S149, 2005.

70. Brüning A, Burger P, Vogel M, Gingelmaier A, Friese K and Burges A: Nelfinavir induces mitochondria protection by ERK1/2-mediated mcl-1 stabilization that can be overcome by sorafenib. Invest New Drugs 28: 535-542, 2010.
71. Crum-Cianflone NF, Hullsiek KH, Marconi V, Weintrob A, Ganesan A, Barthel RV, Fraser S, Roediger MP, Agan B and Wegner S: The impact of nelfinavir exposure on cancer development among a large cohort of HIV-infected patients. J Acquir Immune Defic Syndr 51: 305-309, 2009.

72. Giardino Torchia ML, Ciaglia E, Masci AM, Vitiello L, Fogli M, la Sala A, Mavilio D and Racioppi L: Dendritic cells/natural killer cross-talk: A novel target for human immunodeficiency virus type-1 protease inhibitors. PLoS One 5: e11052, 2010.

73. Bower M, McCall-Peat N, Ryan N, Davies L, Young AM, Gupta S, Nelson M, Gazzard B and Stebbing J: Protease inhibitors potentiate chemotherapy-induced neutropenia. Blood 104: 2943-2946, 2004.

74. Gills JJ and Dennis PA: Perifosine: Update on a novel Akt inhibitor. Curr Oncol Rep 11: 102-110, 2009.

75. Wan X, Harkavy B, Shen N, Grohar P and Helman LJ: Rapamycin induces feedback activation of Akt signaling through an IGF-1R-dependent mechanism. Oncogene 26: 1932-1940, 2007.

76. Carracedo A, Bacelga J and Pandolfi PP: Deconstructing feedback-signaling networks to improve anticancer therapy with mTORC1 inhibitors. Cell Cycle 7: 3805-3859, 2008.

77. Mishra LC, Bhattacharya A, Sharma M and Bhasin VK: HIV protease inhibitors, indinavir or nelfinavir, augment antimalarial action of artemisinin in vitro. Am J Trop Med Hyg 82: 148-150, 2010.

78. Kast RE, Boockvar JA, Brüning A, Cappello F, Chang WW, Cvek B, Dou QP, Duenas-Gonzalez A, Efferth T, Focosi D, et al: A conceptually new treatment approach for relapsed glioblastoma: Coordinated undermining of survival paths with nine repurposed drugs (CUSP9 by the International Initiative for Accelerated Improvement of Glioblastoma Care. Oncotarget 4: 502-530, 2013

79. Cho HY, Thomas S, Golden EB, Gaffney KJ, Hofman FM, Chen TC, Louie SG, Petasis NA and Schönthal AH: Enhanced killing of chemo-resistant breast cancer cells via controlled aggravation of ER stress. Cancer Lett 282: 87-97, 2009.

80. Cho HY, Wang W, Jhaveri N, Torres S, Tseng J, Leong MN, Lee DJ, Goldkorn A, Xu T, Petasis NA, et al: Perillyl alcohol for the treatment of temozolomide-resistant gliomas. Mol Cancer Ther 11: 2462-2472, 2012

81. Homewood CA, Warhurst DC, Peters W and Baggaley VC: Lysosomes, $\mathrm{pH}$ and the anti-malarial action of chloroquine. Nature 235: 50-52, 1972.

82. Shintani T and Klionsky DJ: Autophagy in health and disease: A double-edged sword. Science 306: 990-995, 2004.

83. Allegra A, Penna G, Alonci A, Russo S, Greve B, Innao V, Minardi V and Musolino C: Monoclonal antibodies: Potential new therapeutic treatment against multiple myeloma. Eur J Haematol 90: 441-468, 2013.

84. Allegra A, Sant'antonio E, Penna G, Alonci A, D'Angelo A, Russo S, Cannavò A, Gerace D and Musolino C: Novel therapeutic strategies in multiple myeloma: Role of the heat shock protein inhibitors. Eur J Haematol 86: 93-110, 2011.

85. Allegra A, Penna G, Innao V, Greve B, Maisano V, Russo S and Musolino C: Vaccination of multiple myeloma: Current strategies and future prospects. Crit Rev Oncol Hematol 96: 339-354, 2015.

86. Allegra A, Innao V, Gerace D, Vaddinelli D and Musolino C: Adoptive immunotherapy for hematological malignancies: Current status and new insights in chimeric antigen receptor T cells. Blood Cells Mol Dis 62: 49-63, 2016.

87. Ettari R, Zappalà $\mathrm{M}$, Grasso $\mathrm{S}$, Musolino $\mathrm{C}$, Innao $\mathrm{V}$ and Allegra A: Immunoproteasome-selective and non-selective inhibitors: A promising approach for the treatment of multiple myeloma. Pharmacol Ther 182: 176-192, 2018. 